\title{
Occurrence, Molecular Characterisation and Antibiogram of Water Quality Indicator Bacteria (Pseudomonas Aeruginosa and Enterobacter Aerogenes) in Water Samples from Klang River
}

\author{
Article by Abisola Mercy Olowofeso, Suryadevara Nagaraja \\ MAHSA University Research Laboratory, Jalan SP 2, Bandar Saujana Putra, Malaysia
}

\begin{abstract}
Background and Objectives: Klang River is a $120 \mathrm{~km}$ long extremely polluted river with 11 major tributaries. The pollution is due to the areas where the water passes through. The aims of this research were to identify multidrug resistant Pseudomonas aeruginosa and Enterobacter aerogenes, phenotypically identify their resistance induced traits, and to determine the molecular characterisation of these strains.

Methods: In this research, 30 water samples were collected from different sites along Klang River, their physical properties and biological oxygen demand were estimated. The gram negative multidrug resistant (MDR) strains were isolated, Hodge test, Double Disk Synergy Test and Disk Potentiation Test were done to identify the cause of their resistance induced traits, and plasmid DNA profiling was carried out.

Results: One multidrug resistant (MDR) P. aeruginosa strain was isolated from the 30 samples, it was a non-carbapenemase and metallo- $\beta$-lactamase (MBL) producing strain. 9 E. aerogenes carbapenemase and MBL producing strains were identified, 6 of them were MDR, after extracting the bacteria plasmid DNA, it was confirmed that the bacteria were within the same range as that of control bacterium (marker).

Conclusion: Multidrug resistant $P$. aeruginosa and E. aerogenes were present in the water samples and they had similarly sized DNA fragments to control bacterium.
\end{abstract}

Keywords: Pseudomonas aeruginosa; Enterobacter aerogenes; multidrug resistance; metallo- $\beta$ lactamase.

\section{Introduction}

Enterobacter aerogenes are crucial hospital-acquired pathogens that cause infections such as bacteraemia; lower respiratory tract infections, skin and soft-tissue infections, UTIs, septic arthritis, and ocular infections ${ }^{(1)}$. They usually inhabit soil, water, dairy products and are in GIT of animals including humans. Healthy individuals are not frequently affected. The risk factors for infection with this nosocomial pathogen includes long hospital stay, recent invasive procedures and exposure to antibiotics, the presence of a central venous catheter. And the risk factors for infection with the multidrug-resistant strain includes the recent use of broad-spectrum antibiotic-aminoglycosides and prolonged ICU care ${ }^{(2)}$. Enterobacter aerogenes possess inducible beta-lactamases that are undetectable in vitro but are induce resistance during treatment ${ }^{(3)}$. In a study conducted by Thiolas et al., in 2005, the resistance mechanisms exhibited by the isolated Enterobacter aerogenes pathogens were characterised with alterations of the outer membrane that had caused a decrease in porin and lipopolysaccharide modifications and active efflux $\left({ }^{(4)}\right.$.

Currently, colistin, and polymyxin antibiotics are being substituted as alternative drugs against Gram-negative pathogens due to the resistance exhibited by these gram-negative bacteria to almost all antibiotics but the administration of colistin has been associated with neurotoxic and nephrotoxic effects hence application of alternatives such as biofield treatment which is the electromagnetic field that permeates and surrounds living organisms ${ }^{(5)}$. It is a technique that can alter the sensitivity of antimicrobials against $E$. aerogenes using results obtained from their genotype and phenotype studies (5).

Pseudomonas aeruginosa is a gram-negative opportunistic infection causing bacteria that affects both healthy individuals and immunocompromised patients or those with weakened immune system 
(burn and cancer patients, nosocomial infection- contaminated Automated Urine Analyzer) ${ }^{(6)}$. It is ubiquitous in nature and is found in soil, water, decaying vegetation and animals ${ }^{(7)}$, they possess a characteristic versatility that allows them adapt to a wide range of habitats and even in distilled water and the extremely hot temperatures of whirlpools ${ }^{(5)}$, there have been reports of infections such as folliculitis, conjunctivitis, and otitis externa ${ }^{(9)}$ associated with Pseudomonas aeruginosa in water hence prompting studies to be carried out. According to a study conducted by Fontes et al. in 2011, $P$. aeruginosa found in rivers are biofilm forming ones and can grow under unfavourable conditions such as low oxygen and hence colonise water systems making them serve as environmental reservoirs, chlorine is not $100 \%$ effective against their activities.

The most complicated and multidrug resistant Pseudomonas aeruginosa are the metallo- $\beta$ lactasmase (MBL) producing ones ${ }^{(11)}$ as they can render majority of the antibiotics used against them ineffective by hydrolysing their beta lactamase properties ${ }^{(12)}$. Patients on ampicillin are more susceptible to $P$. aeruginosa gastrointestinal infection due to the inhibition of the activities of normal intestinal flora, hence allowing bacteria to colonize ${ }^{(8) 13)}$, the antibiotics commonly used against $P$. aeruginosa are carbanapems as they can easily penetrate their outer membrane; however this membrane limits the penetration from small hydrophilic molecules and passage of large ones ${ }^{(14)}$. The increased resistance of P.aeruginosa to antibiotics damages tissue, increases hospital expenditure and prolongs hospitalisation stays. Sensitivity analysis showed that the risk of ingesting $P$. aeruginosa in drinking water is low but slightly higher in patients that take $P$. aeruginosa resistant antibiotics ${ }^{(8)(13)}$.

The Malaysian climate is characterised by uniform temperature, high humidity and sufficient rainfall. There are two main seasons, the southwest and northeast monsoon seasons. Altering climatic conditions changes the volume and quality of water hence affecting water usage practices, the intensity and incidence of rainfall alters quality of water in rivers (Klang river), hence the variation in volume of peak discharge. Temperature and flooding increase the risk of exposure to open sewage and inadequate sewage infrastructure increases the probability of infection ${ }^{(15)}$.

Antibiotics are usually used in the treatment of bacterial infections even in aquaculture industries; hence resistance to these drugs has given cause for concern as it affects consumers ${ }^{(16)}$. Water contaminated with this pathogen puts individuals at risk of gastro-enteric diseases ${ }^{(17)}$. Hospital wastewaters contain antimicrobial resistant bacteria about 8 times more than the domestic wastewater ${ }^{(18)}$. Effluents of industries influence pollution in water bodies as they change the physical, chemical and microbiological properties of water bodies ${ }^{(19)}$. Water bodies are sites of genetic exchange where environmental bacteria interact with those from humans and animals via horizontal gene transfer $(\mathrm{HGT})^{(20)}$.

\section{Materials and methods}

\section{Sample collection}

30 water samples were collected into $100 \mathrm{ml}$ sterile containers from these different water sites (Gombak, Batu, Kuyoh, Kerayong, Penchala, Ampang, Klang, and Damansara) that make the Malaysian Klang river, their physical properties (colour, odour, presence of turbidity and debris), temperature and $\mathrm{pH}$ were recorded, samples were also collected in dark amber bottles to determine the dissolved oxygen in them ${ }^{(21)}$, all were then kept in ice boxes until they were transported to the laboratory.

\section{Determination of dissolved oxygen}

To estimate dissolved oxygen of the water samples, the Winkler method was followed ${ }^{(22)}$.

\section{Bacteria isolation}

Each water sample was serially diluted from $10^{-1}$ to $10^{-3}$ using the serial dilution method. $10 \mu$ of each of these diluents were inoculated on Nutrient Agar (NA) via spread plate method (using less populated a glass L-rod) and incubated at $37^{\circ} \mathrm{C}$ for 16 hours, single isolated colonies were picked from less populated culture plates and each sample with two concentrations were inoculated on MacConkey Agar, commercially prepared Blood Agar, Eosin Methylene Blue (EMB) Agar for 24 hours ${ }^{(21)}$ and on Cetrimide Nalidixic Acid Agar (48 hours) ${ }^{(23)}$. 


\section{Characterization and identification}

The colonies on the Nutrient agar, Cetrimide Nalidixic Acid agar, EMB agar, Blood agar and MacConkey agar were observed for morphological characteristics. Pure colonies of EMB and Cetrimide Agars that had expected morphological appearance (or similar appearance) were used to perform identification test- Gram stain and standard microbiology biochemical tests (Indole, Methyl Red, Voges-Proskauer, Mannitol, Citrate, Urease and Triple sugar iron tests) ${ }^{(24)}$.

\section{Multidrug resistance testing}

After the biochemical tests, antibiotic susceptibility tests were carried out on the confirmed bacteria isolates using the Kirby-Bauer and the disc diffusion methods according to the Clinical and Laboratory Standards Institute guidelines ${ }^{(25)(26)}$.

Pure isolates of Enterobacter aerogenes and Pseudomonas aeruginosa were inoculated in nutrient broth and incubated overnight, after overnight incubation, a bacterial lawn was made across Mueller-

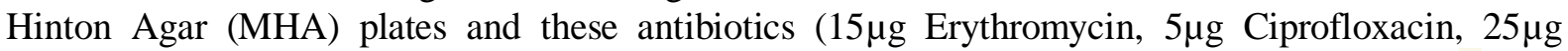

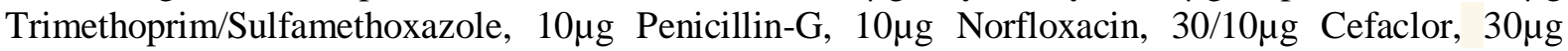

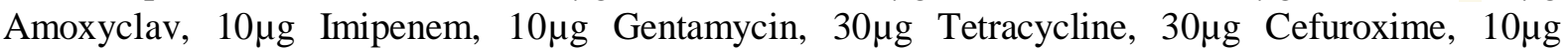
Meropenem) were placed on the surface of MHA plates and incubated at $37{ }^{\circ} \mathrm{C}$ for 18 hours (Jorgensen and Turnidge, 2015), the zone of inhibition around the discs were measured. Isolates that were resistant to three or more classes of antibiotics marked to be active against them were considered multidrug resistant strains.

\section{Phenotyping methods}

\section{Modified hodge test}

This is a test that detects bacteria that produce carbapenemases ${ }^{(28)}$. E. coli ATCC 25922 prepared according to the $0.5 \mathrm{McFarland}$ dilution standard was incubated overnight at $37^{\circ} \mathrm{C}$ and used to make a lawn culture on MHA (for each bacteria isolates). 10 $\mathrm{g}$ imipenem disc was placed at the centre of the each of the plates and the strains were streaked from the end of the disc to the edge of the plate in four different directions, plates were incubated at $37^{\circ} \mathrm{C}$. Carbapenemase production was indicated by a cloverleaf inhibition zone and strains negative for carbapenemase did not have a distorted zone of inhibition ${ }^{(29)}$.

\section{Imipenem-EDTA Double-disc synergy test (DDST)}

Overnight incubated isolates adjusted to the $0.5 \mathrm{McFarland}$ standard were used to make a lawn culture across MHA. 10 $\mu$ Imipenem and EDTA discs were placed on MHA 10mm apart and incubated overnight at $37^{\circ} \mathrm{C}$. An expanded growth inhibition zone between the discs indicated the strains were positive for MBL production and no synergistic zone of inhibition for the non-MBL producing strains ${ }^{(29)}$.

\section{Disk Potentiation Test (DPT)}

Overnight incubated isolates adjusted to the $0.5 \mathrm{McFarland}$ standard were used to make a lawn culture across MHA for each strain, two imipenem discs were placed on MHA, one of which was injected with $5 \mu 1$ of $0.5 \mathrm{M}$ EDTA solution, plates were then incubated overnight, strains with a wider zone of inhibition around EDTA with imipenem were considered MBL producing (Sowmya, 2015).

\section{Plasmid DNA profiling}

The procedure in the GenElute ${ }^{\mathrm{TM}}$ Plasmid Miniprep Kit was followed to extract the DNA from the bacteria isolates.

\section{Electrophoresis}

$50 \mathrm{ml}$ of $1.5 \%$ agarose gel was prepared by dissolving $0.75 \mathrm{~g}$ of agarose in $50 \mathrm{ml}$ of ready to use Tris-EDTA buffer solution and heating it till the solution became clear, after cooling to about $60^{\circ} \mathrm{C}$, $2 \mu 1$ of ethidium bromide was added and mixed well, gel was then poured in the gel tray, the well cutting comb was put in the gel, after it solidified at room temperature the comb was removed. $2 \mu 1$ of 
electrophoresis dye was added to $20 \mu$ of the solutions in the collection tubes (ones with elution solution) and added in the wells. The power cord was connected to the electrophoretic power supply properly. Electrophoresis was run at 120 volts and $90 \mathrm{~mA}$ current until the dye markers migrated a distance of about three-quarter of the gel, process was stopped and the gel was observed under a UV trans-illuminator.

\section{Results}

In this research, 30 water samples were collected along Klang River which extends over Gombak, Batu, Kuyoh, Kerayong, Penchala, Ampang, Klang and Damansara.

For Pseudomonas aeruginosa characterisation, 13-gram negative bacilli were isolated from water samples which were mostly slightly colourless and odourless, with a temperature of $30-32^{\circ} \mathrm{C}, \mathrm{pH}$ of 7.1 - 7.4 (Table 1). These water samples had the highest BOD value (Table 4.2) as compared to the ones with different physical properties. 6 of the 13-gram negative bacilli showed $P$. aeruginosa characterisation (Table 2) on selective Cetrimide agar, MAC and Blood agar. On Cetrimide agar, they showed a yellowish green fluorescence, on blood agar, beta haemolysis was demonstrated by greenish pigment and they were all non-lactose fermenting on MacConkey agar. P. aeruginosa isolation rate was at $3.33 \%$ (Table 3 ) as only one isolate indicated $P$. aeruginosa by being negative to Indole, Methyl Red, Voges-proskauer, Urease and positive to Mannitol, and Citrate tests, strain was motile and showed no hydrogen sulphide or gas production, alkaline slant and butt in TSI tests. The other 5 tested for bacteria that were not $P$. aeruginosa.

For Enterobacter aerogenes isolation, 17-gram negative bacilli were isolated from water samples which were mostly slightly colourless and odourless followed by the turbid and odourless ones, with a temperature of $30-35^{\circ} \mathrm{C}$ and $\mathrm{PH}$ of 6.7-7.2 (Table 1), 6 of the 9 gram negative bacilli showed $E$. aerogenes characterisation on selective EMB agar, MAC and Blood agar. On EMB agar, large pink or purplish mucoid colonies were seen, on blood agar, gamma haemolysis was demonstrated by the medium greyish white colonies and they were all lactose fermenting on MacConkey agar (pink colour). $30 \%$ of water sample isolates were further confirmed by their biochemical tests results by being negative to Indole, Methyl Red, Urease and positive to Voges-Proskauer, Mannitol, and Citrate tests, the strain was motile and showed no hydrogen sulphide or gas production, yellow slant and butt in TSI tests. The other 5 tested for bacteria that were not E. aerogenes.

\section{Multidrug resistant testing}

Table 2 shows the antibiotics that were used against the single strain of $P$. aeruginosa isolated from Klang River and it was highly susceptible to Norfloxacin followed by Meropenem, Cefuroxime, Imipenem, Ciprofloxacin, and Clavulanic acid. It showed resistance to Erythromycin, Trimethoprimsulfamethoxazole, Penicilin-G, Amoxyclav, and Tetracycline (Figure 1).

Table 3 shows the antibiotics that were tested against each of the strains isolated from Klang River. There are 6 multidrug resistant strains with E17 and E18 showing highest resistance (Figure 2) with most of them showing general resistance to Erythromycin, Trimethoprim-sulfamethoxazol, and Penicillin-G.

E14 showed resistance towards Erythromycin, Penicillin, Tetracycline and Cefuroxime, it showed high susceptibility to Clavulanic acid followed by Amoxyclav, Imipenem and Gentamicin, i.e. resistant to 4 of the 8 antibiotics it was tested against (Figure 3).

E17 showed resistance to Erythromycin, Trimethoprim-sulfamethoxazol, Clavulanic acid, Tetracycline and Cefuroxime, it showed high susceptibility to Norfloxacin followed by Imipenem, and Cefuroxime, i.e. resistant to 5 of the 8 antibiotics it was tested against (Figure 4).

E18 showed resistance to Erythromycin, Trimethoprim-sulfamethoxazol, Penicillin-G, Norfloxacin, and Cefuroxime, it showed similar high susceptibility to Clavulanic acid, Amoxyclav followed by Imipenem, i.e. resistant to 5 of the 8 antibiotics it was tested against (Figure 5).

E23 showed resistance to Erythromycin and Penicillin-G, it was highly susceptible to Meropenem, followed by Norfloxacin, Tetracycline, Amoxyclav and Gentamicin. This was resistant to 2 of 8 antibiotics; it is not a multidrug resistant (MDR) strain (Figure 6). 
E24 showed resistance to Erythromycin, Trimethoprim-sulfamethoxazol, Penicillin-G, and Tetracycline, it was highly susceptible to Ciprofloxacin followed by Imipenem, Cefuroxime, and Amoxyclav, i.e. resistant to 4 of the 8 antibiotics it was tested against (Figure 7).

E27 showed resistance to Erythromycin, Trimethoprim-sulfamethoxazol and Penicillin-G, showing high susceptibility to Ciprofloxacin followed by Imipenem, Meropenem, Clavulanic and Genatamicin, it was resistant to 3 of the 8 antibiotics it was tested against (Figure 8).

E30 showed resistance to Erythromycin, Penicillin-G, Tetracycline and Meropenem, it was highly susceptible to Cefuroxime followed by Norfloxacin, Ciprofloxacin and Clavulanic acid, i.e. resistant to 4 of the 8 antibiotics it was tested against (Figure 9).

E11 showed resistance to Erythromycin and Penicillin-G, it was highly susceptible to Amoxyclav followed by Norfloxacin, Cefuroxime, Ciprofloxacin, Meropenem and Clavulanic acid, this is not a MDR strain as it only showed resitance to 2 antibiotics (Figure 10).

E26 showed resistance to only Trimethoprim-sulfamethoxazol, and high susceptibility to Imipenem followed by Amoxyclav, Ciprofloxacin, Norfloxacin, Calvulanic acid, Gentamicin and Cefuroxime (Figure 11). This not a MDR strain.

\section{Modified hodge test}

The $P$. aeruginosa strain was tested for carbapenemase production and it tested negative as no clover or zone of inhibition was formed around the carbapenem (imipenem) disc used (Fig. 1).

The E14 strain tested negative for carbapenemase production by the lack of a zone of inhibition around the carbapenem (imipenem) disc used, however E17, E23, E 18, E24, E27 and E30 tested positive for carbapenemase production and was represented by the clover or zone of inhibition around the imipenem discs (Table 4).

\section{Imipenem-EDTA double-disc synergy test (DDST)}

The $P$. aeruginosa strain was tested with Imipenem and $10 \mu$ EDTA discs and it was MBL positive. All the 6 strains of E. aerogenes were tested and were MBL positive, this was indicated by the expanded growth/inhibition zone between the discs (Table 4).

\section{Disk potentiation test (DPT)}

The wider zone of inhibition around the Imipenem disc impregnated with EDTA than the plain Imipenem confirmed P20, E14, E17, E23, E 18, E24, E27 and E30 were MBL producing strains (Table 4).

\section{Electrophoresis}

Plasmid DNA was extracted and electrophoresed. Plasmid DNA of the bacteria was within the same range as of control bacteria (Figure 12).

\section{Discussion}

The need for safe and healthy water supplies has created a cause for public health concern about the rising pollution in water bodies (Klang River), there is now pressure on appropriate authorities to carry out due action to reduce the rate of pollution of this water bodies, hence the studies of micro flora found in them- pathogens, and faecal organisms ${ }^{(30)} .15$ of the water samples were slightly clear and odourless with mean $\mathrm{pH}$, Temperature, Dissolved oxygen and BOD of $7.06,30.87^{\circ} \mathrm{C}, 6.23 \mathrm{mg} / \mathrm{L}$, and $3.93 \mathrm{mg} / \mathrm{L}$ respectively. The normal BOD value range for moderately polluted rivers is $2-8 \mathrm{mg} / \mathrm{L}$, hence these water sites were moderately polluted hence higher dissolved oxygen levels that will permit growth of bacteria. Most of the gram-negative bacilli were isolated from these samples.

Two samples had debris in them but were odourless with mean $\mathrm{pH}$, Temperature, Dissolved oxygen and BOD of $7.10,30.50^{\circ} \mathrm{C}, 5.95 \mathrm{mg} / \mathrm{L}$ and $2.77 \mathrm{mg} / \mathrm{L}$ respectively. These samples had the lowest BOD value that still indicated that water was moderately polluted but with enough dissolved oxygen for bacteria and aquatic life to thrive.

Nine of the water samples were turbid and odourless with mean $\mathrm{pH}$, Temperature, Dissolved oxygen and BOD of $7.02,33.33^{\circ} \mathrm{C}, 7.56 \mathrm{mg} / \mathrm{L}, 3.28 \mathrm{mg} / \mathrm{L}$ respectively. BOD value indicates water was moderately polluted and still had enough dissolved oxygen for bacteria and aquatic life to thrive. 
Carbapenems are usually used against MDR strains P20 was susceptible to the carbapenemsImipenem and Meropenem used. E14, E17, E23, E 18, E24, E27 and E30 were resistant to imipenem and all but E30 were resistant to Meropenem. In a study conducted in India to detect the genes encoding carbapenem resistance among Enterobacter species, $53.84 \%$ of the isolates showed reduced susceptibility to Imipenem. $17.14 \%$ of these isolates were confirmed to be Enterobacter aerogenes ${ }^{(31)}$, although the susceptibility range was reduced just like that of E14, E17, E23, E18, E24, E27 and E30, most of the strains still showed resistance to Imipenem and Meropenem. 15 $\mu \mathrm{g}$ Erythromycin,

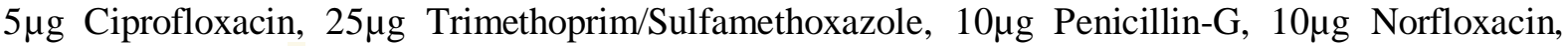

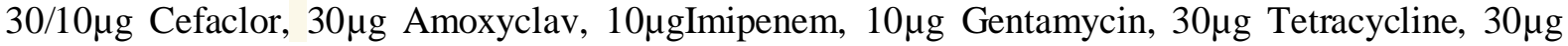
Cefuroxime, and $10 \mu \mathrm{g}$ Meropenem were used against P. aeruginosa and it exhibited high resistance to 5 of these 12. In a study conducted by Adesoji et al., 2015, P. aeruginosa was noted to be more resistant to older generation antibiotics (Trimethoprim/Sulfamethoxazole, Tetracycline) than the new generation ones (Nalidic acid, Gentamicin, and Kanamycin) and this older generation antibiotic resitance was exhibited in this $P$. aeruginosa isolation study. MDR rate of $P$. aeruginosa isolated from clinical samples in Iran, Nepal and Malaysia were $100 \%, 20.69 \%$ and $19.6 \%$ respectively ${ }^{(32)}$.

A study of $P$. aeruginosa isolated from river water and clinical smaples show resitance to cotrimoxazole than they do Gentamicin and Tetracycine, however isolates from river water alone show higher sensitivity to Ciprofloxacin ${ }^{(33)}$.

Phenotyping methods are dependent on the ability of metal chelators - EDTA and thiol-based compounds to inhibit MBL activity ${ }^{(34)}$. EDTA-(DDST and CPT) are used to detect MBL producing strains, CPT is more sensitive than DDST while Modified Hodge test can only detect if a strain is carbapenemase producing one as metal dependence of carbapenemase is not confirmed because EDTA is not used, ${ }^{(35)}$,These tests are cheap to perform, easy and give reliable and ideal results ${ }^{(36)}$.In this study, the P20 and E14 were not carbapenemase producing strains but were MBL producing ones. The other 5 of the 6 strains (83.33\%) were both MBL and carbapenemase producing strains.

Conclusively, multi-drug resistant Pseudomonas aeruginosa and Enterobacter aerogenes were present in water samples from Klang River, most of the E. aerogenes were carbapenemase producing while the single $P$. aeruginosa was not. All the strains of the two bacteria were MBL producing ones, this increased contamination and presence of MBL producing strains can be associated with the industries, hospitals, and increased pollution around the places Klang River passes through.

Multidrug resistant bacteria in water systems contribute to the wide-scale transfer of resistance genes in the environment thereby posing health hazard to humans and animals. Untreated water sources are a major threat to the public health and frequent antibiotic abuse has induced increased antibiotic resistance ${ }^{(16)}$.

Integrated antibiotic resistant surveillance system, promotion of controlled use of antibiotics and holistic one health approach are recommended in both the clinical and agricultural settings to prevent and control multidrug resistant bacteria in areas the Klang River passes ${ }^{(7)}$. Some of the effluents in the river water are from hospitals, the infection control measure applied in Recife Brazil can also be applied (identifying blaSPM-1 genes and disseminate clones to different hospitals ${ }^{(38)}$. Results of Hodge test can be made more ideal or improved by the addition of zinc sulphate to the Mueller Hinton $\operatorname{agar}^{(39)}$.

The band size was along the same size as that of the marker DNA. 16S rRNA sequencing can be done to further identify and confirm the strain of bacteria isolates.

\section{Significance of study}

This study highlighted the presence of MDR isolates of $P$. aeruginosa and E. aerogenes in water samples from Klang River and this is associated with the high rates of pollution from the disposal of household, industrial and hospital wastes around and into the water bodies increasing the risk of infection and prolonged hospitalisation from lack of response to empirical therapy, increased cost of health care and possibly complications in poorly managed situations. 


\section{Limitations of study}

$16 \mathrm{~S}$ rRNA sequencing can be done to further identify and confirm the strain of bacteria isolates.

Table 1. Physical properties, $\mathrm{pH}$, Temperature, DO and BOD value of water samples

\begin{tabular}{|c|c|c|c|c|c|}
\hline Sample & Physical properties & $\mathrm{pH}$ & $\begin{array}{l}\text { Temperature } \\
\left({ }^{\circ} \mathrm{C}\right)\end{array}$ & Dissolved Oxygen $(\mathrm{mg} / \mathrm{L})$ & $\begin{array}{l}\text { BOD value } \\
(\mathrm{mg} / \mathrm{L})\end{array}$ \\
\hline 1 & Slightly clear, odourless & 6.5 & 30 & 3.13 & 2.95 \\
\hline 2 & Slightly clear, odourless & 6.5 & 31 & 2.50 & 2.00 \\
\hline 3 & Slightly clear, odourless & 6.6 & 30 & 2.20 & 1.87 \\
\hline 4 & Debris present, odourless & 7.1 & 30 & 5.43 & 2.33 \\
\hline 5 & Debris present, odourless & 7.1 & 31 & 6.47 & 3.20 \\
\hline 6 & Slightly clear, odourless & 7.2 & 31 & 5.97 & 3.00 \\
\hline 7 & Slightly clear, odourless & 7.0 & 30 & 7.20 & 4.85 \\
\hline 8 & Slightly clear, odourless & 6.8 & 31 & 8.07 & 5.00 \\
\hline 9 & Clear, odourless & 6.8 & 30 & 6.43 & 2.50 \\
\hline 10 & Clear, punget smell & 6.7 & 32 & 7.10 & 4.60 \\
\hline 11 & Slightly clear, pungent smell & 6.7 & 33 & 7.27 & 4.60 \\
\hline 12 & Slightly clear, pungent smell & 6.8 & 32 & 6.93 & 3.85 \\
\hline 13 & Turbid, odourless & 6.4 & 33 & 8.90 & 3.90 \\
\hline 14 & Turbid, odourless & 6.7 & 34 & 6.10 & 2.45 \\
\hline 15 & Turbid, odourless & 6.9 & 34 & 6.17 & 2.30 \\
\hline 16 & Turbid, odourless & 7.0 & 33 & 6.90 & 2.85 \\
\hline 17 & Slightly clear, odourless & 7.4 & 32 & 9.35 & 4.50 \\
\hline 18 & Slightly clear, odourless & 7.2 & 32 & 4.23 & 2.75 \\
\hline 19 & Slightly clear, odourless & 7.4 & 31 & 5.33 & 3.72 \\
\hline 20 & Slightly clear, odourless & 7.4 & 32 & 9.70 & 6.20 \\
\hline 21 & Slightly clear, odourless & 7.4 & 31 & 10.30 & 7.56 \\
\hline 22 & Slightly clear, odourless & 7.1 & 32 & 7.50 & 4.10 \\
\hline 23 & Slightly clear, odourless & 7.1 & 30 & 5.50 & 3.30 \\
\hline 24 & Slightly clear, odourless & 7.1 & 30 & 6.70 & 3.70 \\
\hline 25 & Slightly clear, odourless & 7.2 & 30 & 5.70 & 3.43 \\
\hline 26 & Turbid, odourless & 7.2 & 32 & 6.80 & 2.50 \\
\hline 27 & Turbid, odourless & 7.2 & 35 & 8.30 & 3.50 \\
\hline 28 & Turbid, odourless & 7.4 & 33 & 9.30 & 5.10 \\
\hline 29 & Turbid, odourless & 7.2 & 31 & 7.70 & 3.23 \\
\hline 30 & Turbid, odourless & 7.2 & 35 & 7.90 & 3.65 \\
\hline
\end{tabular}


DOI: $10.21522 /$ TIJBMS.2016.04.01.Art003

ISSN: $2519-500 \mathrm{X}$

Table 2. Antibiogram of Pseudomonas aeruginosa (P20) isolate

\begin{tabular}{|l|l|}
\hline Antibiotics & P20 \\
\hline $15 \mu \mathrm{g}$ Erythromycin & Resistant \\
\hline $5 \mu \mathrm{g}$ Ciprofloxacin & $14 \mathrm{~mm}$ \\
\hline $25 \mu \mathrm{g}$ Trimethoprim-sulfamethoxazole & Resistant \\
\hline $10 \mu \mathrm{g}$ Penicillin-G & Resistant \\
\hline $10 \mu \mathrm{g}$ Norfloxacin & $23 \mathrm{~mm}$ \\
\hline $30 / 10$ Clavulanic acid & $10 \mathrm{~mm}$ \\
\hline $30 \mu \mathrm{g}$ Amoxyclav & Resistant \\
\hline $10 \mu \mathrm{g}$ Imipenem & $18 \mathrm{~mm}$ \\
\hline $10 \mu \mathrm{g}$ Gentamicin & $9 \mathrm{~mm}$ \\
\hline $30 \mu \mathrm{g}$ Tetracycline & Resistant \\
\hline $30 \mu \mathrm{g}$ Cefuroxime & $18 \mathrm{~mm}$ \\
\hline $10 \mu \mathrm{g}$ Meropenem & $21 \mathrm{~mm}$ \\
\hline
\end{tabular}




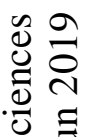

总

急

产

\begin{tabular}{|c|c|c|c|c|c|c|c|c|}
\hline 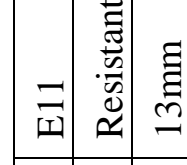 & & & ถุํำ & 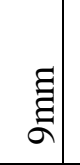 & 思 & 1 & & 을 \\
\hline 䆫 & & & 党 & (్) & & 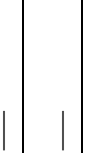 & & 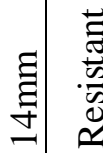 \\
\hline ત્રેચ & $\approx$ & 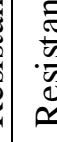 & & $\underline{\underline{a}}$ & & & & 18 \\
\hline đ્ઞ & & & 妾 & 言 & 声 & 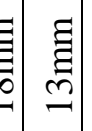 & & $\stackrel{\Xi}{\stackrel{5}{*}}$ \\
\hline 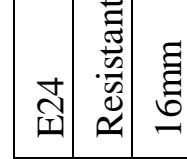 & & 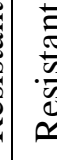 & & | & 就高 & 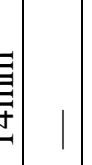 & & \\
\hline 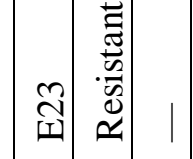 & & & ฐี่ & 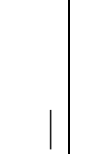 & $\stackrel{\Xi}{\Xi}$ & : & & हn: \\
\hline 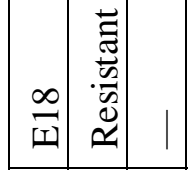 & & & 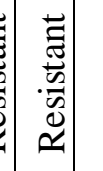 & & 䍖 & & & 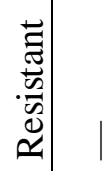 \\
\hline | & & & ฐิ & 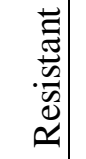 & & 思 & & 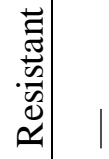 \\
\hline | & & & & & & 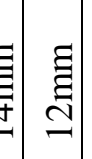 & & \\
\hline 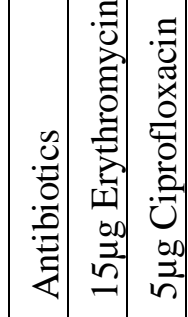 & 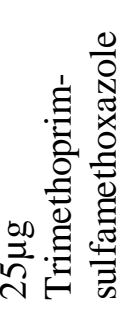 & & 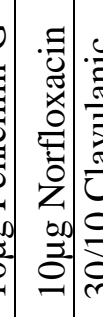 & & 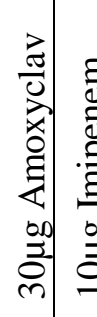 & 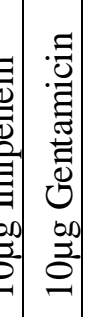 & & 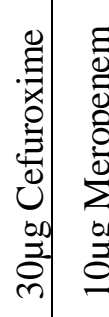 \\
\hline
\end{tabular}


Table 4. Detection of carbapenemase, beta-lactamase and MBL producing gram negative E. aerogenes

\begin{tabular}{|l|l|l|l|l|l|l|l|}
\hline $\begin{array}{l}\text { Phenotypin } \\
\text { g tests }\end{array}$ & E14 & E17 & E23 & E18 & E24 & E27 & E30 \\
\hline Hodge Test & Negative & Positive & Positive & Positive & Positive & Positive & Positive \\
\hline DDST & Positive & Positive & Positive & Positive & Positive & Positive & Positive \\
\hline DPT & Positive & Positive & Positive & Positive & Positive & Positive & Positive \\
\hline
\end{tabular}

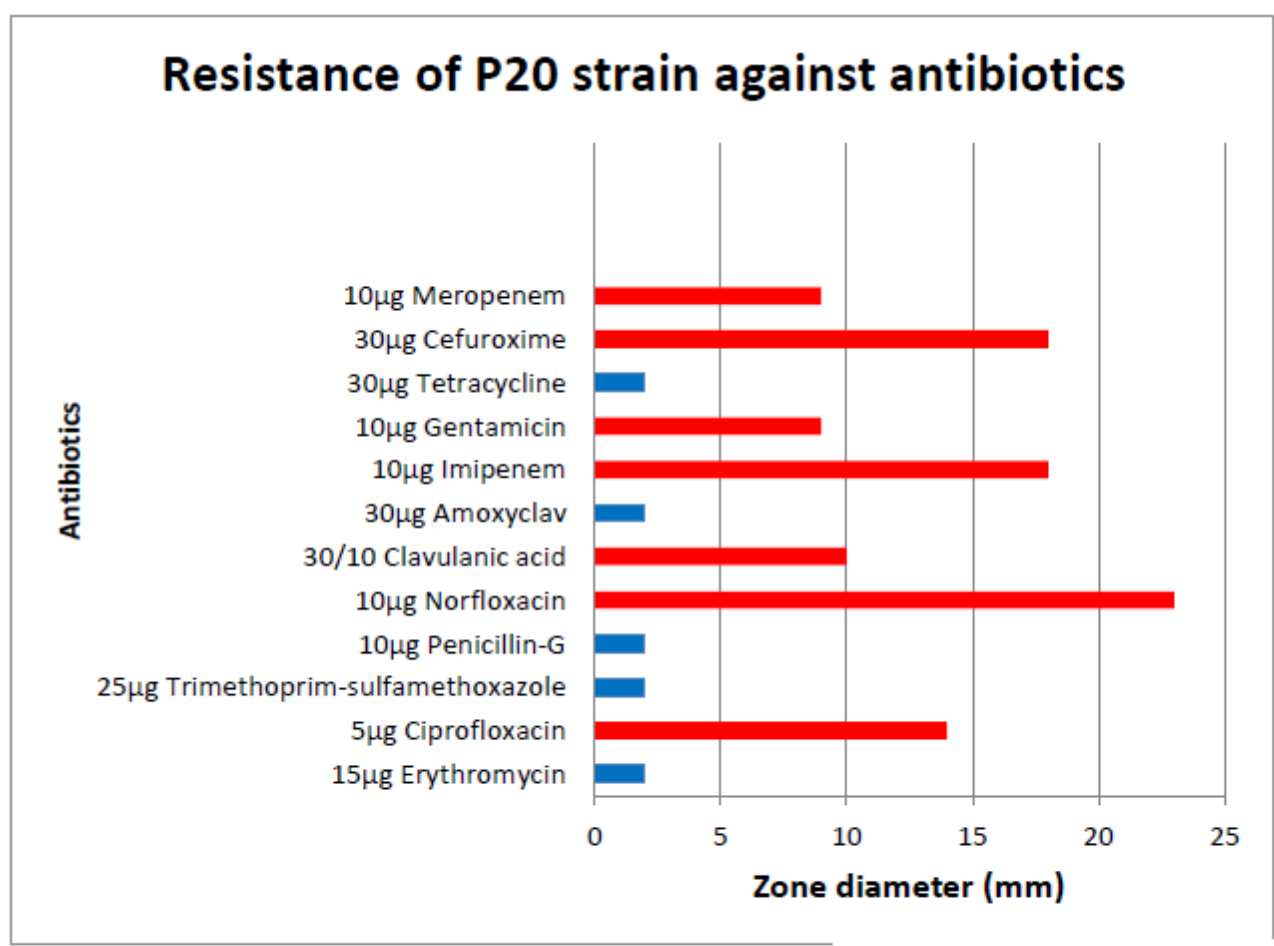

Resistance is represented by $2 \mathrm{~mm}$

Figure 1. Resistance of P20 strain against antibiotics

\section{E. aerogenes Resistance (\%)}

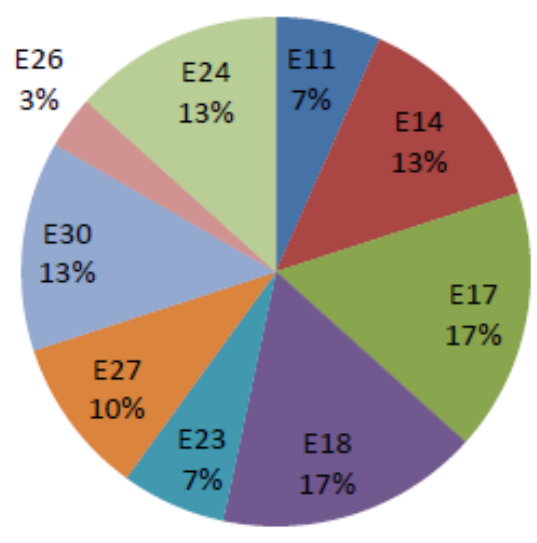

Figure 2. Rate of resistance of the different E. aerogenes strains to antibiotics 
DOI: $10.21522 /$ TIJBMS.2016.04.01.Art003

ISSN: $2519-500 \mathrm{X}$

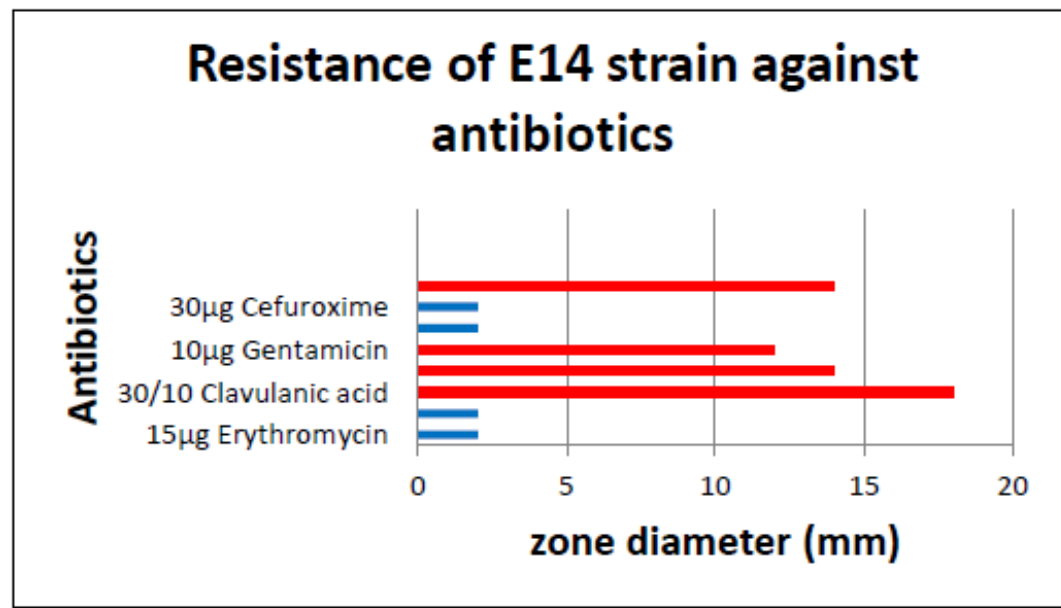

Resistance is represented by $2 \mathrm{~mm}$

Figure 3. Resistance of E14 strain against antibiotics

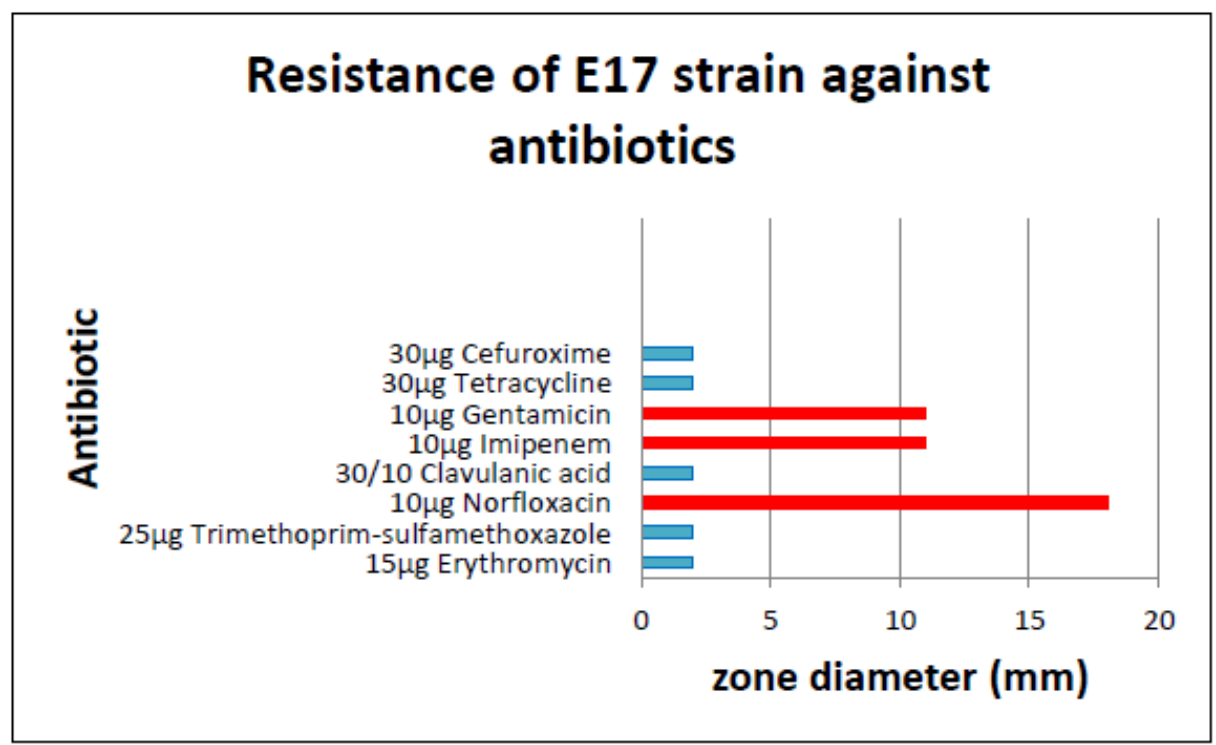

Resistance is represented by $2 \mathrm{~mm}$

Figure 4. Resistance of E17 strain against antibiotics 


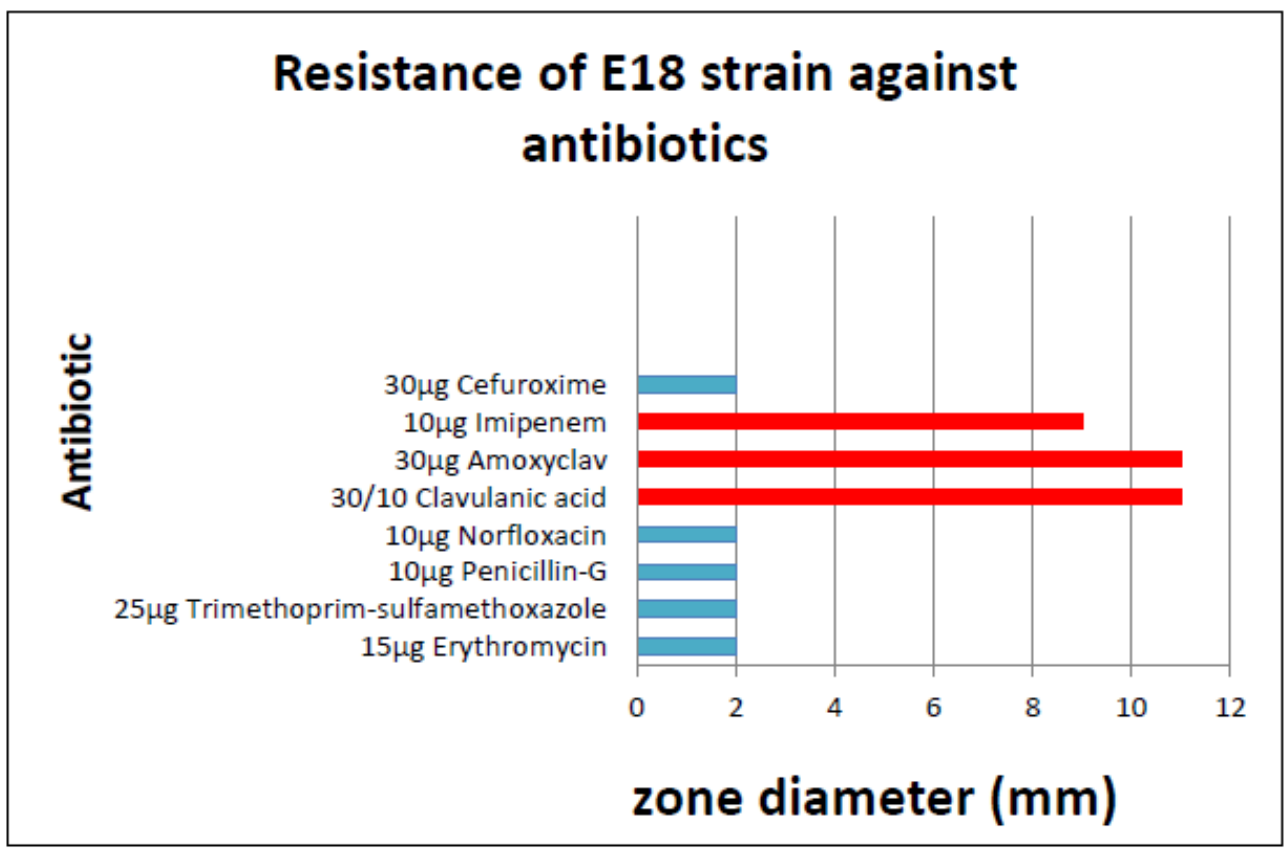

\section{Resistance is represented by $2 \mathrm{~mm}$}

Figure 5. Resistance of E18 strain against antibiotics

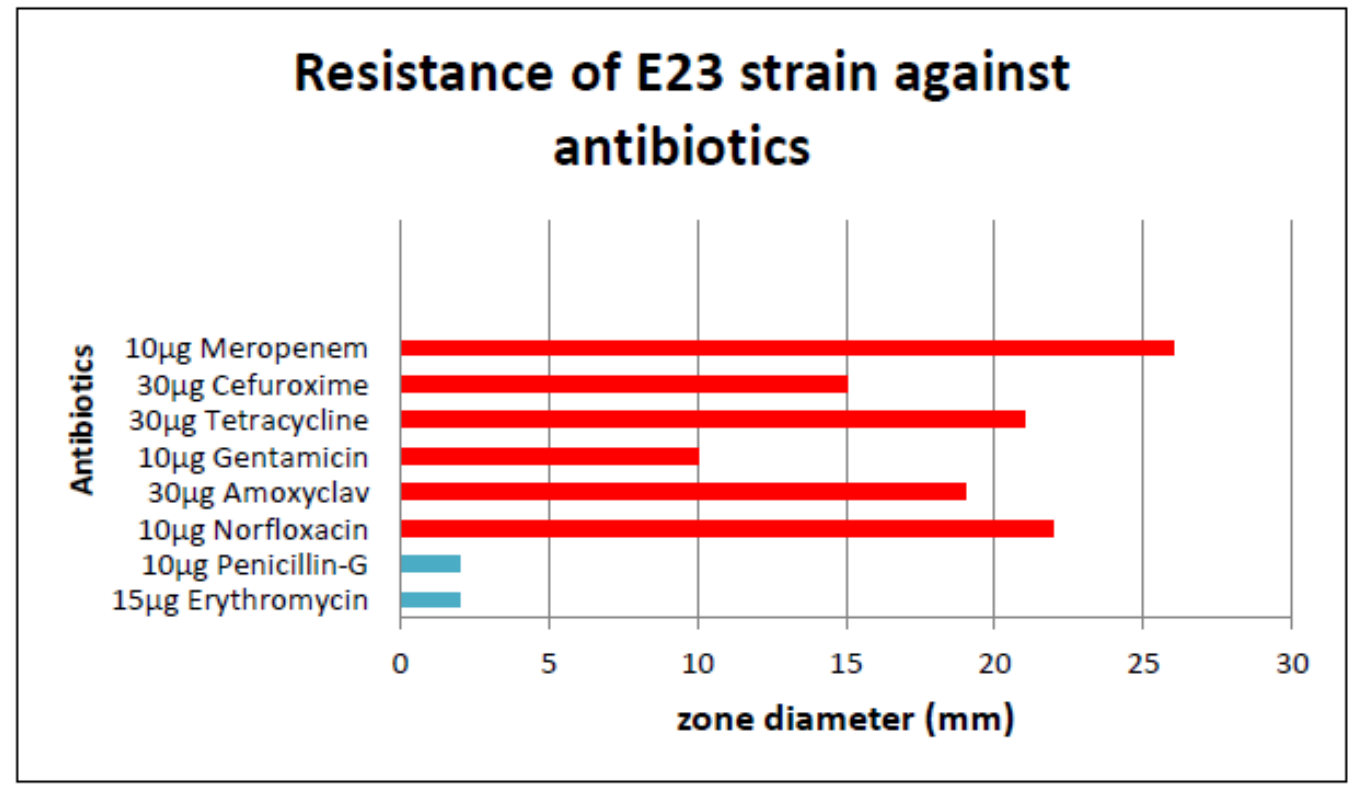

Resistance is represented by $2 \mathrm{~mm}$

Figure 6. Resistance of E23 strain against antibiotics 
DOI: $10.21522 /$ TIJBMS.2016.04.01.Art003

ISSN: $2519-500 \mathrm{X}$

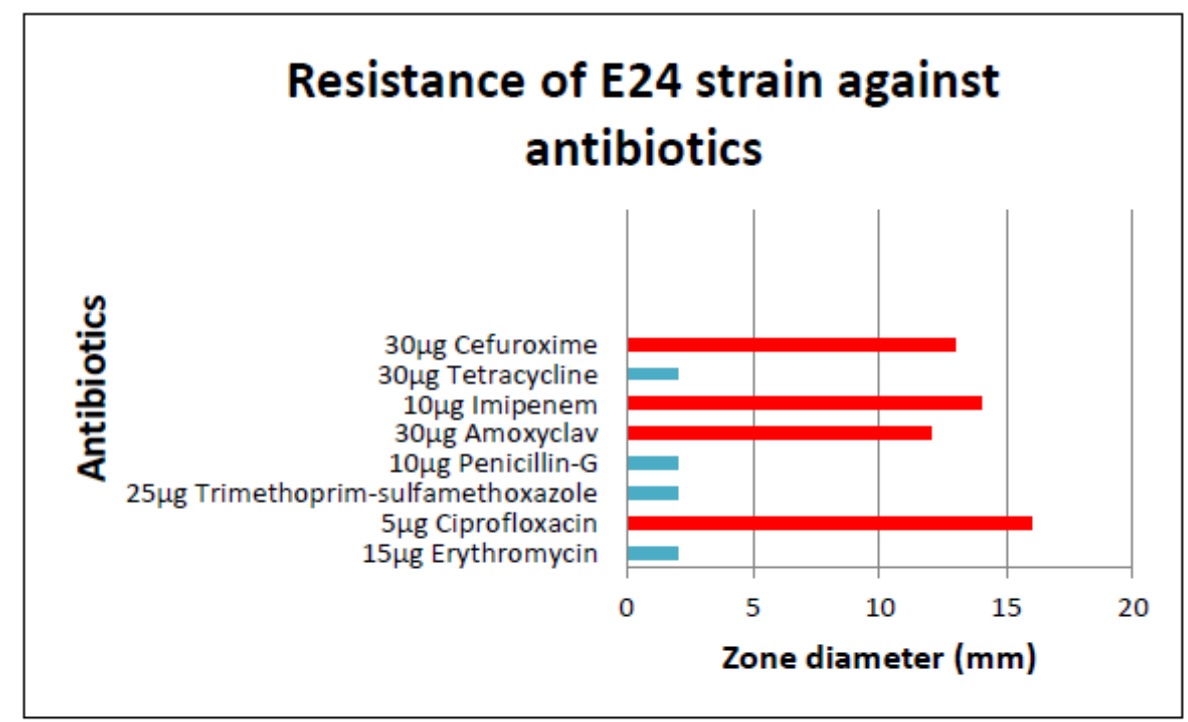

Resistance is represented by $2 \mathrm{~mm}$

Figure 7. Resistance of E24 strain against antibiotics

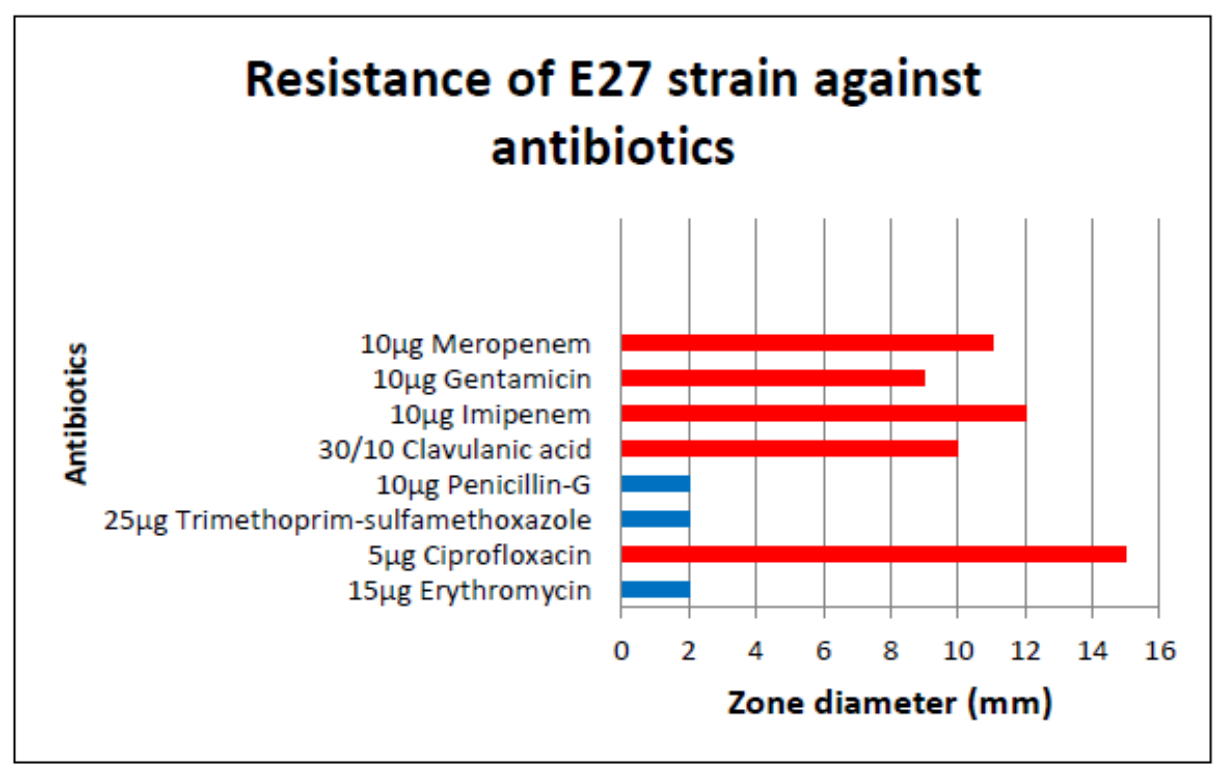

Resistance is represented by $2 \mathrm{~mm}$

Figure 8. Resistance of E27 strain against antibiotics 


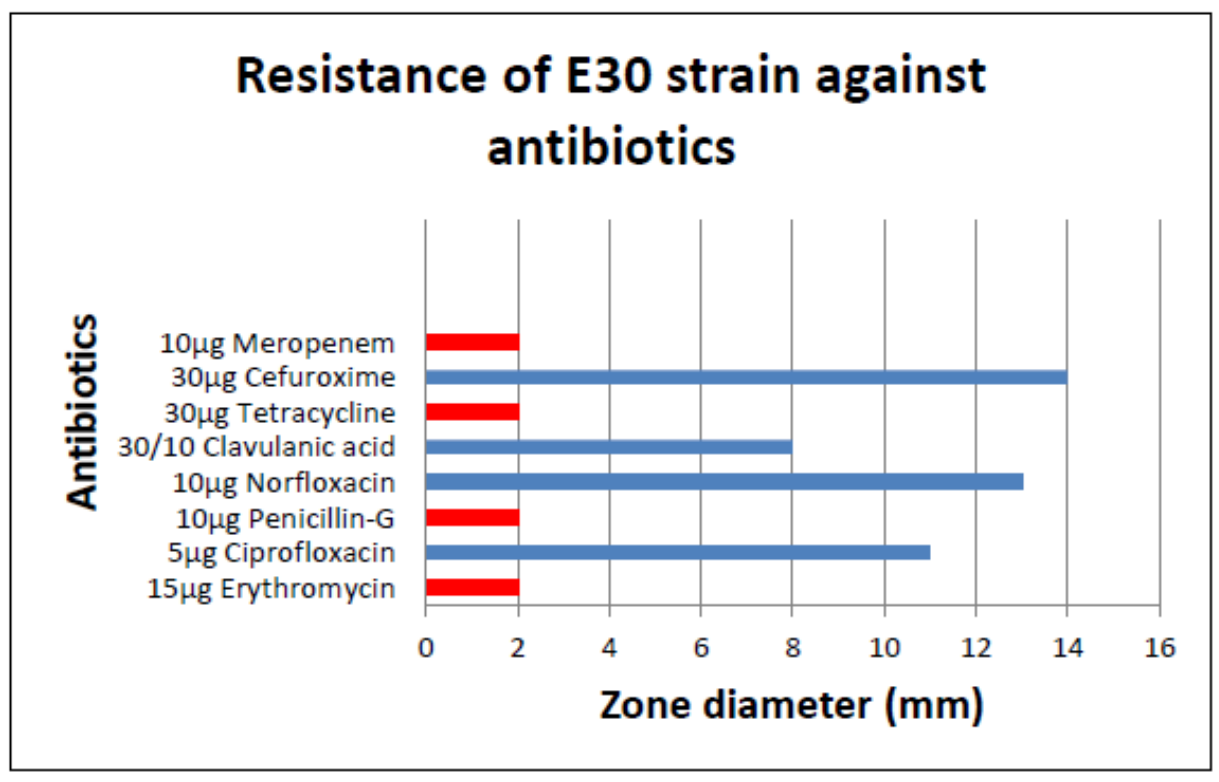

\section{Resistance is represented by $2 \mathrm{~mm}$}

Figure 9. Resistance of E30 strain against antibiotics

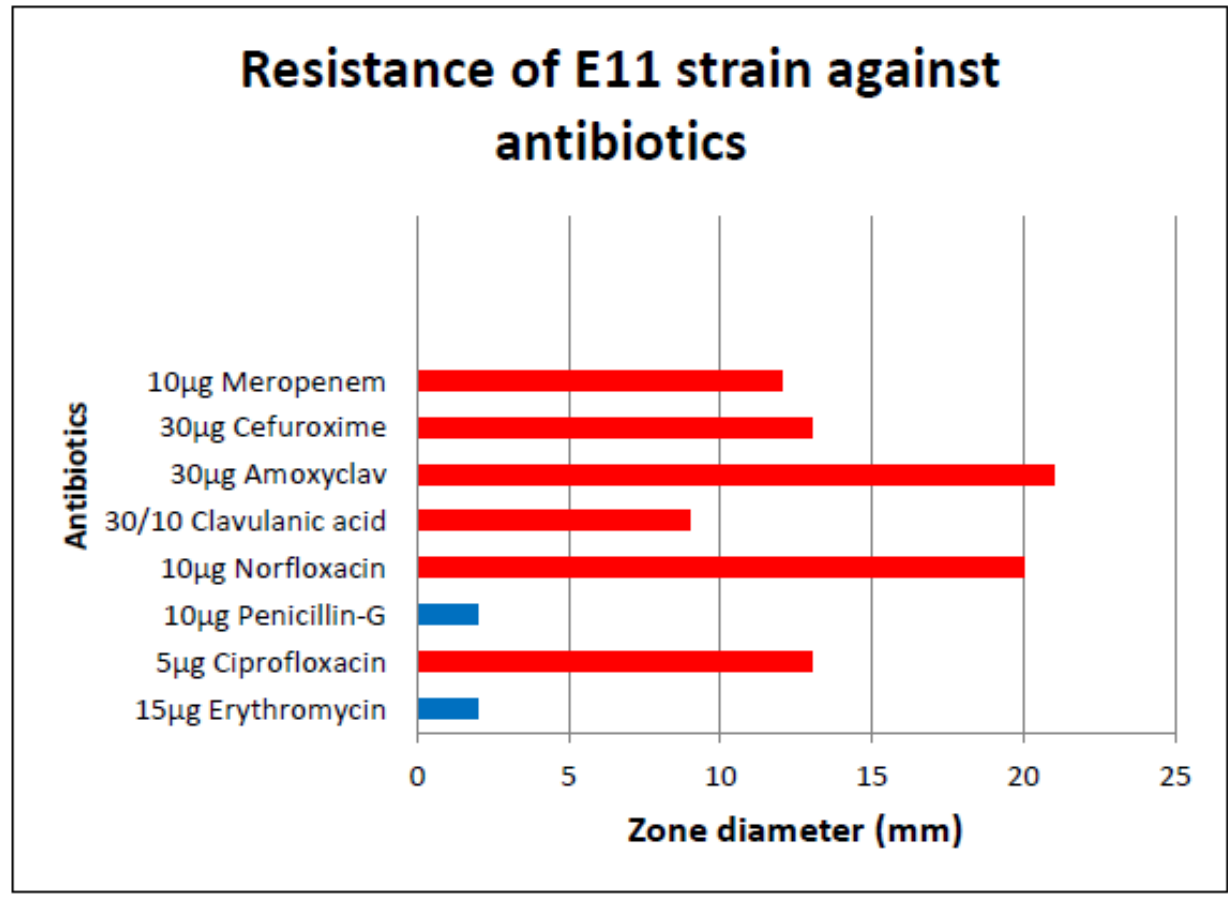

\section{Resistance is represented by $2 \mathrm{~mm}$}

Figure 10. Resistance of E11 strain against antibiotics\ 
DOI: $10.21522 /$ TIJBMS.2016.04.01.Art003

ISSN: 2519-500X

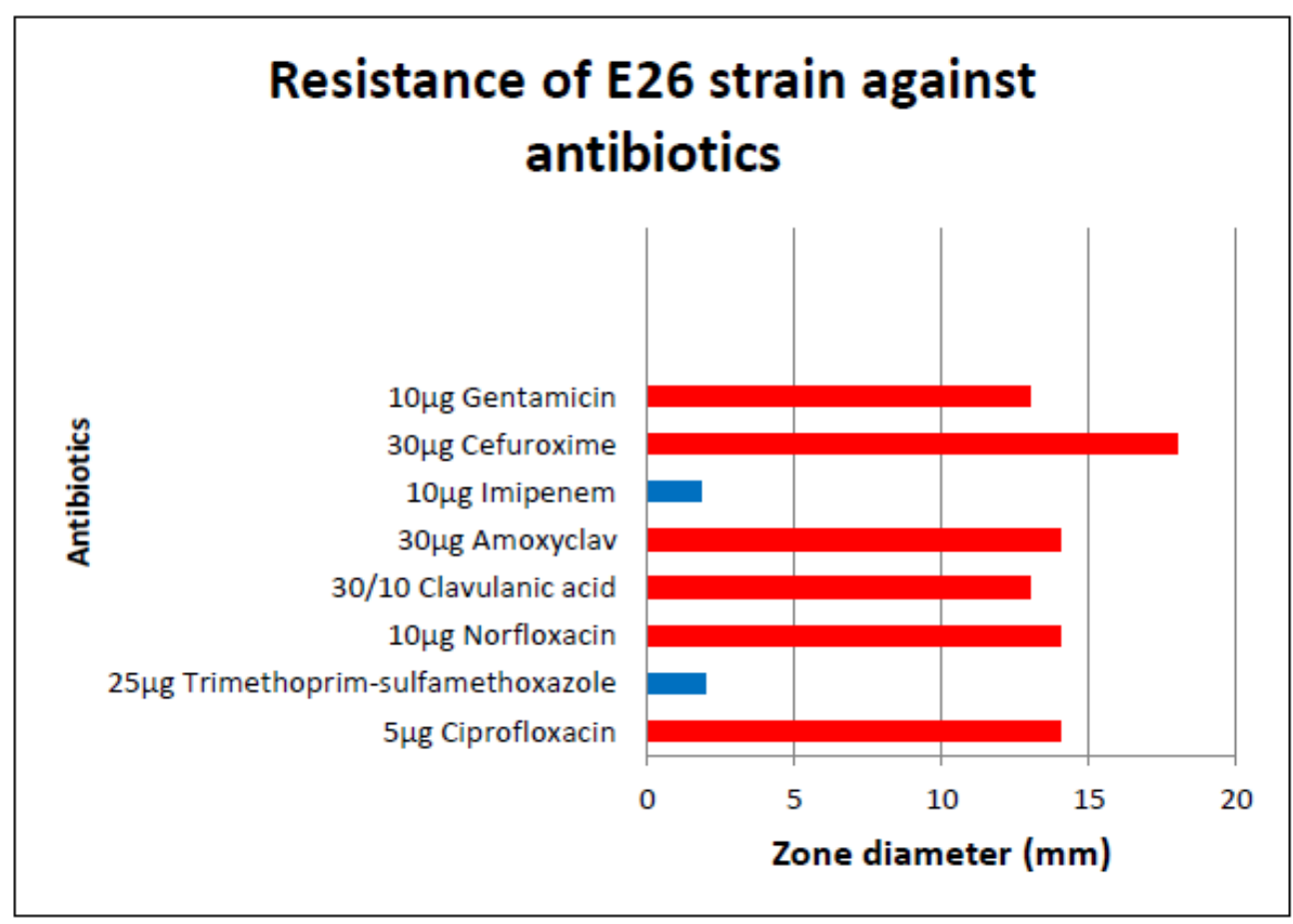

Resistance is represented by $2 \mathrm{~mm}$

Figure 11. Resistance of E26 strain against antibiotics

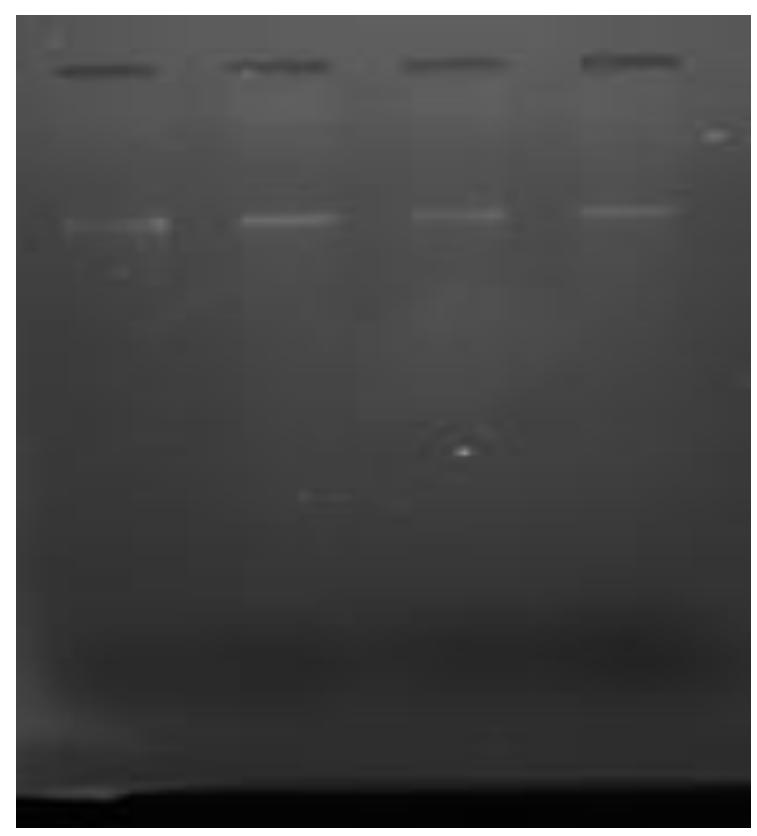

Figure 12. Plasmid DNA profiling

P E17 E18 P20

Lane P- control Pseudomonas aeruginosa ATCC 9027 (marker)

Lane E17-MDR Enterobacter aerogenes

Lane E18- MDR Enterobacter aerogenes

Lane P20- MDR Pseudomonas aeruginosa 


\section{References}

[1]. Lockhart, S., Abramson, M., Beekmann, S., Gallagher, G., Riedel, S., Diekema, D., Quinn, J. and Doern, G. (2007). Antimicrobial Resistance among Gram-Negative Bacilli Causing Infections in Intensive Care Unit Patients in the United States between 1993 and 2004. Journal of Clinical Microbiology, 45(10), pp.3352-3359.

[2]. Hidron, A., Edwards, J., Patel, J., Horan, T., Sievert, D., Pollock, D. and Fridkin, S. (2008). NHSN Annual Update: Antimicrobial-Resistant Pathogens Associated with Healthcare-Associated Infections: Annual Summary of Data Reported to the National Healthcare Safety Network at the Centers for Disease Control and Prevention, 2006-2007 •. Infection Control and Hospital Epidemiology, 29(11), pp.996-1011.

[3]. Thiolas, A., Bollet, C., La Scola, B., Raoult, D. and Pages, J. (2005). Successive Emergence of Enterobacter aerogenes Strains Resistant to Imipenem and Colistin in a Patient. Antimicrobial Agents and Chemotherapy, 49(4), pp.1354-1358.

[4]. Mallea, M., Chevalier, J., Bornet, C., Eyraud, A., Davin-Regli, A., Bollet, C. and Pages, J. (1998). Porin alteration and active efflux: two in vivo drug resistance strategies used by Enterobacter aerogenes. Microbiology, 144(11), pp.3003-3009.

[5]. Jana, S., Trivedi, M. and Branton, A. (2015). Characterization of Phenotype and Genotype of Biofield Treated Enterobacter aerogenes. Translational Medicine, 05(04).

[6]. Hallin, M., Deplano, A., Roisin, S., Boyart, V., De Ryck, R., Nonhoff, C., Byl, B., Glupczynski, Y. and Denis, O. (2012). Pseudo-Outbreak of Extremely Drug-Resistant Pseudomonas aeruginosa Urinary Tract Infections Due to Contamination of an Automated Urine Analyzer. Journal of Clinical Microbiology, 50(3), pp.580-582.

[7]. Adesoji, A., Ogunjobi, A. and Olatoye, I. (2015). Molecular characterization of selected multidrug resistant Pseudomonas from water distribution systems in southwestern Nigeria. Annals of Clinical Microbiology and Antimicrobials, 14(1).

[8]. Mena KD and Gerba CP (2009). Risk assessment of Pseudomonas aeruginosa in water. Reviews of Environmental Contamination and Toxicology, 201, pp.71-115.

[9]. Craun, G., Calderon, R. and Craun, M. (2005). Outbreaks associated with recreational water in the United States. International Journal of Environmental Health Research, 15(4), pp.243-262.

[10]. Fontes, L., Neves, P., Oliveira, S., Silva, K., Hachich, E., Sato, M. and Lincopan, N. (2011). Isolation of Pseudomonas aeruginosa Coproducing Metallo- -Lactamase SPM-1 and 16S rRNA Methylase RmtD1 in an Urban River. Antimicrobial Agents and Chemotherapy, 55(6), pp.3063-3064.

[11]. Mehul S Chaudhari Tanuja B Javadekar Govind Ninama Neelam Pandya Jivraj Damor (2011) A study of metallo-beta-lactatamase producing pseudomonas aeruginosa in clinical samples of S.S.G. hospital. Natl J Med Res, 1 (2), 60-63.

[12]. Pitout, J., Gregson, D., Poirel, L., McClure, J., Le, P. and Church, D. (2005). Detection of Pseudomonas aeruginosa Producing Metallo Lactamases in a Large Centralized Laboratory. Journal of Clinical Microbiology, 43(7), pp.3129-3135.

[13]. Mena KD and Gerba CP (2009). Risk assessment of Pseudomonas aeruginosa in water. Reviews of Environmental Contamination and Toxicology, 201, pp.71-115.

[14]. Ranjan, S., Sreenivasa Babu, P. and Banashankari, G. (2014). Comparison of epidemiological and antibiotic susceptibility pattern of metallo-beta-lactamase-positive and metallo-beta-lactamase-negative strains of pseudomonas aeruginosa. Journal of Laboratory Physicians, 6(2), p.109.

[15]. Corcoran, E., Nellemann, C., Baker, E., Bos, R., Osborn, D. and Savelli, H. (2010). Sick water? The central role of wastewater management in sustainable development. 1st ed. Arendal: UNEP/GRID-Arendal.

[16]. Ventola, C. L. (2015). The Antibiotic Resistance Crisis: Part 1: Causes and Threats. Pharmacy and Therapeutics, Pharmacy and Therapeutics, 40(4), 277-283.

[17]. Fawell, J. (2003). Contaminants in drinking water. British Medical Bulletin, 68(1), pp.199-208.

[18]. Artemova, T., Gerardin, Y., Dudley, C., Vega, N. and Gore, J. (2015). Isolated cell behavior drives the evolution of antibiotic resistance. Molecular Systems Biology, 11(7), pp.822-823.

[19]. Hussain, M. and Rao, T. (2013). Effect of Industrial Effluents on Surface Water Quality - A Case Study of Patancheru, Andhra Pradesh, India. Current World Environment Journal, 8(3), pp.445-454.

[20]. Coutinho, F., Silveira, C., Pinto, L., Salloto, G., Cardoso, A., Martins, O., Vieira, R. and Clementino, M. (2014). Antibiotic Resistance is Widespread in Urban Aquatic Environments of Rio de Janeiro, Brazil. Microbial Ecology, 68(3), pp.441-452. 
[21]. Okokwo Iheanyi, Damilola, Adejoye Oluseyi; Adeola, Ogunnusi Tolulope; A, Enobong; B, Shittu Olufunke. (2008). Microbiological and physicochemical analysis of different water samples used for domestic purposes in Abeokuta and Ojota, Lagos State, Nigeria. African Journal of Biotechnology, pp. 617-621.

[22]. Carpenter, J. (1965). THE CHESAPEAKE BAY INSTITUTE TECHNIQUE FOR THE WINKLER DISSOLVED OXYGEN METHOD. Limnology and Oceanography, 10(1), pp.141-143.

[23]. Slekovec, C., Plantin, J., Cholley, P., Thouverez, M., Talon, D., Bertrand, X. and Hocquet, D. (2012). Tracking Down Antibiotic-Resistant Pseudomonas aeruginosa Isolates in a Wastewater Network. PLoS ONE, 7(12), p.e49300.

[24]. Cappuccino, J. and Sherman, N. (2007). Microbiology: A Laboratory Manual. 8th ed.

[25]. CLSI Institute 2011

[26]. Bashir D, Thokar MA, Fomda BA, Bashir G, Zahoor D, Ahmad S, Toboli AS (2011). Detection of metallo-beta-lactamase (MBL) producing Pseudomonas aeruginosa at a tertiary care hospital in Kashmir. Afr. J. Microbiol. Res. 5(2):164-172.

[27]. Jorgensen, J. and Turnidge, J. (2015). Susceptibility Test Methods: Dilution and Disk Diffusion Methods*. Manual of Clinical Microbiology, 11th Edition, pp.1253-1273.

[28]. Amjad, A., Mirza, I., Abbasi, S., Farwa, U., Malik, N., \& Zia, F. (2011). Modified Hodge test: A simple and effective test for detection of carbapenemase production. Iranian Journal of Microbiology, 3(4), pp.189193.

[29]. Sowmya, G., Shivappa, Ranjitha Shankaregowda, Raghavendra Rao M, Rajeshwari K G, Madhuri Kulkarni (2015). Detection of Metallo-beta lactamase production in clinical isolates of Nonfermentative Gram negative bacilli. IOSR Journal of Dental and Medical Sciences (IOSR-JDMS), pp. 43-48.

[30]. Canhoto, O. and Magan, N. (2005). Electronic nose technology for the detection of microbial and chemical contamination of potable water. Sensors and Actuators B: Chemical, 106(1), pp.3-6.

[31]. Khajuria, A., Praharaj, A., Kumar, M. and Grover, N. (2014). Carbapenem Resistance among Enterobacter Species in a Tertiary Care Hospital in Central India. Chemotherapy Research and Practice, 2014, pp.1-6.

[32]. Nasreen, M., Sarker, A., Malek, M., Ansaruzzaman, M. and Rahman, M. (2015). Prevalence and Resistance Pattern of Pseudomonas aeruginosa isolated from Surface Water. Advances in Microbiology, 05(01), pp.74-81.

[33]. Bhalerao DS, Roushani S, Kinikar AG, Akhter I. (2010). Study of Metallo-beta lactamase producing Pseudomonas aeruginosa in Pravara Rural Hospital. Pravara Med Rev; 2(3).

[34]. Manoharan, A., Chatterjee, S., Mathai, D. and SARI Study Group (2010). Detection and characterization of metallo beta lactamases producing Pseudomonas aeruginosa. Indian Journal of Medical Microbiology, 28(3), p.241.

[35]. Kali, A. (2013). Detection of metallo-beta-lactamase producing Pseudomonas aeruginosa in intensive care units. Australasian Medical Journal, 6(12), pp.686-693.

[36]. Qu TT1, Zhang JL, Wang J, Tao J, Yu YS, Chen YG, Zhou JY, Li LJ. (2009). Evaluation of phenotypic tests for detection of metallo-beta-lactamase-producing Pseudomonas aeruginosa strains in China. J Clin Microbiol 47(4): pp.1136-1142.

[37]. Jácome, P., Alves, L., Cabral, A., Lopes, A. and Maciel, M. (2012). Phenotypic and molecular characterization of antimicrobial resistance and virulence factors in Pseudomonas aeruginosa clinical isolates from Recife, State of Pernambuco, Brazil. Revista da Sociedade Brasileira de Medicina Tropical, 45(6), pp.707712.

[38]. Lee, K., Lim, Y., Yong, D., Yum, J. and Chong, Y. (2003). Evaluation of the Hodge Test and the Imipenem-EDTA Double-Disk Synergy Test for Differentiating Metallo- -Lactamase-Producing Isolates of Pseudomonas spp. and Acinetobacter spp. Journal of Clinical Microbiology, 41(10), pp.4623-4629.

[39]. Ataee R. A., Tavana A. m., Hosseini S. M. J., Moridi K., and Zadegan M. G. (2012). A Method for Antibiotic Suseptibility Testing: Applicable and Accurate. Jundishapur J Microbiol. 5(1), pp. 341-345.I

[40]. Cox, B. (2003). A review of dissolved oxygen modelling techniques for lowland rivers. The Science of The Total Environment, 314-316, pp.303-334.

[41]. Diene, S., Merhej, V., Henry, M., El Filali, A., Roux, V., Robert, C., Azza, S., Gavory, F., Barbe, V., La Scola, B., Raoult, D. and Rolain, J. (2012). The Rhizome of the Multidrug-Resistant Enterobacter aerogenes Genome Reveals How New "Killer Bugs" Are Created because of a Sympatric Lifestyle. Molecular Biology and Evolution, 30(2), pp.369-383.37. 